\title{
PENGARUH ETOS KERJA DAN DISIPLIN KERJA TERHADAP PENINGKATAN EKONOMI PEKERJA KULI ANGKUT (MANOL) DI UPT TPI MAYANGAN
}

Khoirul Anam, Ainur Rifqi

Universitas Nurul Jadid Paiton Probolinggo

\begin{abstract}
This study aims to find out 1) the effect of work ethic on improving porters' economy (manol) at UPT TPI Mayangan 2) to determine the effect of work discipline on improving porters economy 3) to determine the effect of work ethic and work discipline on improving porters economy. Data on work ethics and work discipline is obtained through distributing questionnaires to 30 porters, while data on economic improvement is obtained through interviews with 30 porters. Data is analyzed using multiple linear regression. The research findings show that work ethic has no effect on improving the economy. Other test results show there is no effect of work discipline on improving the economy. Likewise simultaneously the work ethic and work discipline have no influence on the improvement of the porters' economy at the UPT TPI Mayangan.
\end{abstract}

Keywords : Work Ethics, Work Discipline, and economic improvement.

Correspondence to : kodepajha@gmail.com

\begin{abstract}
ABSTRAK
Penelitian ini bertujuan untuk mengetahui 1) pengaruh etos kerja terhadap peningkatan ekonomi kuli angkut (manol) di UPT TPI Mayangan 2) untuk mengetahui pengaruh disiplin kerja terhadap peningkatan ekonomi kuli angkut 3)untuk mengetahui pengaruh etos kerja dan disiplin kerja terhadap peningkatan ekonomi kuli angkut. Data etos kerja dan disiplin kerja didapatkan melalui penyebaran kuesioner kepada 30 kuli angkut, sedangkan data peningkatan ekonomi di peroleh melalui wawancara kepada 30 kuli angkut. Data di analisis dengan menggunakan regresi linear berganda. Temuan penelitian menunjukkan bahwa etos kerja tidak memiliki pengaruh terhadap peningkatan ekonomi. Hasil pengujian lain menunjukkan tidak ada pengaruh disiplin kerja terhadap peningkatan ekonomi. Begitu juga secara simultan etos kerja dan disiplin kerja tidak memiliki pengaruh pada peningkatan ekonomi kuli angkut di UPT TPI Mayangan.
\end{abstract}

Kata kunci : : $\quad$ :tosKerja, Disiplin Kerja, dan peningkatan ekonomi.

Korespondensi $\quad$ : kodepajha@gmail.com

\section{PENDAHULUAN / INTRODUCTION}

Semakin meningkatnya pengetahuan manusia, maka semakin meningkat pula kebutuhan yang harus dipenuhinya. Semakin meningkatnya kebutuhan hidup mendorong seseorang untuk bekerja dan mendapatkan penghasilan dari pekerjaan tersebut. Penghasilan yang didapatkan berguna untuk mencukupi kebutuhan pokok dan kebutuhan lain. Untuk mencapai hal tersebut seseorang 
harus memiliki semangat kerja yang tinggi serta disiplin kerja yang luar biasa.

Perusahaan dalam meraih keberhasilan mencapai tujuannya tergantung tidak hanya pada keunggulan teknologi, dana operasi yang tersedia, fasilitas atau infrastruktur, tetapi juga tergantung pada aspek sumber daya manusia (Erlina, et al., 2017). Kinerja karyawan dalam bekerja didasarkan pada kemampuan, perilaku, dan kontribusi terhadap perusahaan (Firmansyah, et al., 2017), untuk meraih sukses diperlukan seperangkat sikap, kondisi mental, kemampuan psikologis, dan perilaku kerja yang disiplin. Peran yang sangat vital dalam mewujudkan prestasi seorang pekerja adalah dirinya sendiri. Bagaimana dia memiliki semangat dan etos kerja yang tinggi untuk dapat memberikan pengaruh positif pada lingkungannya (Sinamo, 2011:18).

Anoraga (1992) berpendapat bahwa keberhasilan dalam persaingan kerja tidak hanya membutuhkan kemampuan dan keahlian saja tetapi juga diperlukan adanya dedikasi, semangat, dan kejujuran dalam bekerja. Karyawan yang memahami dan menerima tujuan perusahaan akan merasa sesuai dengannya akan merasa bertanggung jawab dalam mewujudkan tujuan perusahaan (Mochklas, et at., 2018). Seseorang yang mencapai hasil harus memiliki pemikiran dan etika dalam bekerja sebagai pandangan hidup manusia. Pekerja yang memiliki pemikiran yang luhur mengenai pekerjaannya dapat bekerja dengan senang hati. Suatu pandangan dan sikap terhadap kerja dikenal dengan istilah etos kerja. Etos kerja merupakan sikap, pandangan, kebiasaan, ciri-ciri atau sifat mengenai cara bekerja yang dimiliki seseorang, suatu golongan atau suatu bangsa (Dodi, et al., 2013).

Etos kerja adalah semangat kerja yang terlihat dalam cara seseorang menyikapi pekerjaan, motivasi yang melatar belakangi melakukan suatu pekerjaan (Fadillah, 2010). Berdasarkan dari berbagai penjelasan tersebut, maka dapat disimpulkan bahwa etos kerja merupakan hal sangat penting yang perlu diperhatikan lebih lanjut untuk mendapatkan disiplin kerja yang tinggi.

Menurut penelitian Merpaung (2013) menyatakan bahwa disiplin kerja sangat penting bagi pekerja maupun organisasi atau kelompok karena disiplin kerja dapat mempengaruhi produktifitas kerja, sedangkan produktifitas kerja secara tidak langsung berpengaruh pada kesejahteraan atau peningkatan ekonomi setiap pekerja. Pekerja yang bekerja penuh disiplin akan memberikan konstribusi positif terhadap semua kegiatan perusahaan dalam mencapai tujuannya (Mochklas \& Mahardhika, 2019).

\section{KAJIAN LITERATUR}

Ekonomi merupakan salah satu ilmu sosial yang mempelajari kehidupan manusia yang berkaitan dengan produksi,distribusi,dan konsumsi.Istil ah ekonomi sendiri berasal dari bahasa Yunani,yaitu oĩkos (oikos) yang berarti keluarga,rumah tangga dan vó $\mu$ o (nomos) yang berarti peraturan,aturan,hukum.Secara garis besar,ekonomi diartikan sebagai aturan rumah tangga atau manajemen rumah tangga.Sementara yang dimaksud dengan ahli ekonomi atau ekonom adalah orang menggunakan konsep ekonomi, dan data dalam bekerja. Smith (2018:28) berpendapat bahwa Ekonomi ialah penyelidikan tentang keadaan dan sebab adanya kekayaan suatu golongan bahkan negara.

Maslow (2010) mengatakan bawah Ekonomi adalah salah satu bidang pengkajian yang mencoba menyelesaikan masalah keperluan atas kehidupan manusia melalui penggemblengan segala sumber ekonomi yang ada dengan berasaskan prinsip serta teori tertentu dalam suatu sistem ekonomi yang dianggap efektif dan efisien. 
Kertajaya, (2006:9) menyatakan bahwa Ekonomi adalah plat form dimana sektor industri melekat diatasnya. Samuelson, (2003) mengungkapkan Ekonomi merupakan cara-cara yang dilakukan oleh manusia dan kelompoknya untuk memanfaatkan sumbersumber yang terbatas untuk memperoleh berbagai komoditi dan mendistribusikannya untuk dikonsumsi oleh masyarakat banyak.

Sebagimana Rosulullah bersabda: "Bekerjalah untuk dunia mu, seakan-akan engkau akan hidup selama-lamanya dan beribadahlah untuk akhirat seakan-akan engkau akan mati besok", Umar bin Khottob pernah berkata: Maka hendaklah kamu menghitung dirimu sendiri, sebelum datang hari dimana engkau akan menghitungkan dan hal ini sejalan dan searah dengan firman Allah yang bersabda:" Hendaklah kamu menghitung diri hari ini untuk mempersiapkan hari esok (Q.S. 59:18)

Kuznets (1971) yang juga merupakan seorang presiden American Economic Assosiation pada tahun 1954 berpendapat bahwa peningkatan ekonomi merupakan kenaikan pola serta gaya hidup suatu golongan dalam kehidupan sehari-hari.

Dari definisi tersebut berikut beberapa contoh ciri-ciri meningkatnya ekonomi seseorang ataupun golongan:

1.penampilan yang selalu rapi serta berhiaskan aksesoris elegan.

2.bertambahnya barang-barang yang terggolong mewah.

3.terjadinya perubahan struktural yang meningkat.

\section{Pengertian etos kerja}

Dalam Kamus Besar Bahasa Indonesia di jelaskan bahwa etos adalah pandangan hidup yang khas dari suatu golongan masyarakatat. Sedangkan kerja adalah semangat yang menjadi ciri tersendiri pada suatu kelompok. Etos kerja adalah mesin penggerak yang harus di miliki oleh setiap manusia agar dapat menyelesaikan pekerjaan dengan baik. dari berbagai seminar dan lokal karya selalu ditampilkan, bahwa etos kerja bangsa Indonesia masih rendah.

Sedangkan Etos Kerja Menurut Max Weber dalam Peters \& Siswosoebroto (1988) adalah sikap masyarakat atau golongan terhadap makna bekerja sebagai pendorong keberhasilan usaha dan pembangunan dalam bekerja. Menurut Bukhori (1989), menyatakan bahwa etos berasal dari bahasaYunani, Ethos yang berarti "ciri sifat" atau istiadat", atau juga "kecenderungan moral, pandangan hidup" yang dimiliki oleh seseorang,atau golongan atau suatu bangsa. Dengan menggunakan etos kerja, pekerjaan yang dilakukan dapat mencapai hasil yang memuaskan serta tepat waktu.

Menurut Anoraga(1992), etos kerja adalah suatu pandangan dan sikap suatu golongan atau masyarakat terhadap kerja. jika pandangan dan sikap dalam bekerja di nilai baik maka etos kerja golongan atau masyarakat itu akan tinggi. Sebaliknya kalau menilai pekerjaan tidak berarti untuk kelangsungan hidup manusia maka dapat di pastikan gologan atau masyarakat itu tidak memiliki etos kerja yang baik. Apalagi sama sekali tidak ada pandangan dan sikap terhadap kerja. Maka karna hal tersebut agar muncul suatu pandangan atau sikap yang bisa menghargai pekerjaan sebagai suatu hal yang mulia perlu adanya semangat serta motivasi yang baik.

\section{Tujuan Etos kerja}

Setelah dijelaskan tentang definisi etos kerja di atas, maka berikutnya adalah tentang tujuan etos kerja. Seorang pekerja memang dituntut untuk memiliki etos kerja yang tinggi karena selain bekerja. Pekerja juga mempunyai tujuan untuk beberapa hal:

1) Mencari nafkah.

2) Memberikan masa depan yang lebih layak bagi anak cucu. 
3) Mencerminkan jati dirinya,pandangan pandangan serta prinsip prinsip yang ada dalam dirinya.

\section{Karakteristik Etos Kerja}

Orang yang mempunyai dan menghayati etos kerja akan tampak dalam sikap dan tingkah lakunya. Ada semacam bisikan hati untuk terus menerus memperbaiki diri, mencapai prestasi, dan tampil sebagai bagian dari masyarakat yang terbaik Indikator etos kerja yang profesional menurut Sinamo (2011) antara lain :

1. Kerja adalah rahmat : harus bekerja tulus penuh syukur.

2. Kerja adalah amanah : harus bekerja penuh dengan integritas.

3. Kerja adalah panggilan : harus bekerja tuntas penuh dengan tanggung jawab.

4. Kerja adalah aktualisasi : harus bekerja penuh semangat.

5. Kerja adalah ibadah : harus bekerja serius dengan penuh pengabdian

6. Kerja adaah seni : harus bekerja kreatif penuh suka cita.

7. Kerja adalah kehormatan : harus bekerja unggul penuh dengan ketekunan.

8. Kerja adalah pelayanan : harus bekerja sempurna penuh kerendahan hati.

\section{Pengertian disiplin kerja}

Hasibuan (2004:213) berpendapat bahwa kedisiplinan adalah kesadaran dan kesediaan seseorang mentaati semua peraturan dan norma-norma sosial yang berlaku. Menurut Hani (2001) disiplin adalah "kegiatan manajemen untuk menjalankan standar-standar organisasional". Pendapat lain mengatakan bahwa disiplin kerja merupakan "suatu sikap dan perilaku seseorang yang berniat untuk mentaati segala peraturan organisasi yang didasarkan atas kesadaran diri untuk menyesuaikan dengan peraturan organisasi" (Helmi, 1996). Disiplin kerja bagi pekerja sangat penting,bagi suatu golongan dalam rangka mewujudkan tujuan-tujuan yang telah di tentukan. Sikap disiplin kerja yang dimiliki oleh pekerja sangat penting bagi suatu organisasi atau golongan dalam rangka mewujudkan tujuan-tujuan yang sudah di targetkan. Tanpa disiplin kerja yang baik sulit bagi suatu golongan menghasilkan hasil yang maksimal.

Hal ini mendukung terwujudnya motivasi dan terwujudnya tujuan suatu golongan.

Kedisiplinan suatu golongan dikatakan baik, jika sebagian besar pekerja mentaati setiap ketentuan yang ada. Sanksi sangat dibutuhkan untuk meningkatkan kedisiplinan dan membina pekerja supaya mentaati semua peraturan golongan.

\section{Indikator disiplin kerja}

Menurut Hasibuan (2006) indikator disiplin kerja yaitu:

1) Sikap

Mental dan perilaku yang berasal dari kesadaran atau kerelaan dirinya sendiri dalam melaksanakan tugas dan peraturan golongan atau organisasi.

2) Norma

Peraturan tentang apa yang boleh dan apa yang tidak boleh dilakukan oleh seseorang selama dalam bekerja dan sebagai acuan dalam bersikap.

3) Tanggung jawab

Merupakan kemampuan dalam menjalankan tugas dan peraturan dalam golongan atau organisasi.

4) Menyelesaikan pekerjaan pada waktu yang telah ditentukan.

seseorang harus bertanggung jawab atas pekerjaannya dengan menyelesaikan pekerjaan tepat pada waktu yang ditentukan.

Faktor-faktor yang mempengaruhi disiplin kerja

Adanya disiplin kerja dalam suatu golongan atau organisasi akan membuat seseorang dapat menjalankan tugas-tugas 
yang dibebankan kepadanya dengan baik.seseoorang yang disiplin dan patuh terhadap norma-norma yang berlaku dalam organisasi atau golongan dapat meningkatkan produktivitas dan prestasi kerja yang bersangkutan.

Pada dasarnya fungsi-fungsi yang mempengaruhi tingkat kedisiplinan kerja suatu golongan atau organisasi menurut Hasibuan (2013) antara lain:

$>$ Tujuan dan kemampuan

$>$ Teladan pemimpin

$>$ Keadilan

$>$ Sanksi hukuman

$>$ Hubungan kemanusiaan

\section{Hubungan Etos Kerja dan Peningkatan Ekonomi}

Etos kerja dan peningkatan ekonomi adalah suatu hal yang tidak dapat dipisahkan. Masalah ekonomi dalam sebuah komunitas masyarakat adalah merupakan suatu pranata sosial yang sangat penting.

Pada penelitian sebelumnya di jelaskan bahwa bekerja adalah fitrah dan sekaligus merupakan salah satu identitas manusia, sehingga bekerja didasarkan pada prinsip-prinsip keyakinan, bukan saja menunjukkan fitrah tetapi sekaligus meningkatkan martabat diri manusia (Tasmara, 1995: 2).

Secara umum, fungsi manifest sistem ekonomi adalah mengatur hubungan antar pelaku ekonomi dan meningkatkan produktivitas ekonomi semaksimal mungkin Di dalam masyarakat tradisional, sejumlah besar kegiatan ekonomi di organisir dan muncul dari keluarga. Proses-proses ekonomi mulai banyak diambil alih oleh sistem lain, misalnya oleh sistem pendidikan yang bertugas mencetak sarjana-sarjana ulung yang diperlukan untuk mengisi lowongan kerja pada perusahaan atau pabrik-pabrik modern.

Keluarga dalam masyarakat modern bukan lagi pusat dan sarana dari sitem ekonomi, bukan lagi sumber tenaga kerja dan teknologi yang eksklusif kendati tetap penting sebagai sumber-sumber norma dari tenaga kerja. Keluarga di sini menciptakan motif dasar yang diperlukan di dalam kerja manusia (Narwoko \& Bagong, 2013).

Dari penjelasan tersebut, tampak etos kerja sangat berpengaruh atas peningkatan ekonomi suatu keluarga maupun golongan. Pembangunan ekonomi di Indonesia merupakan bagian penting dari pembangunan nasional yang dimulai sejak pelita pertama yang bertujuan untuk meningkatkan kesejahteraan dan pendapatan masyarakat. Selain peningkatan pendapatan lewat pertumbuhan produksi dan kesempatan kerja, proses pembangunan ekonomi juga membawa perubahan mendasar dalam struktur ekonomi nasional (Sasono, 2014).

Dalam teori ekonomi klasik seperti yang dijelaskan oleh Taringan (2005: 45) bahwa agar masyarakat diberikan kebebasan seluas-luasnya dalam menentukan kegiatan ekonomi apa yang dirasa baik untuk dilakukannya. Rumah tangga adalah pemilik faktor produksi yang tersedia dalam perekonomian. Sektor ini menyediakan tenaga kerja dan tenaga usahawan (Sukirno, 2003: $37)$.

Di sisi lain pembangunan dan peningkatan ekonomi sebagai serangkaian usaha perekonomian untuk mengembangkan kegiatan ekonominya sehingga infrastruktur lebih banyak tersedia, perusahaan semakin banyak dan semakin berkembang, taraf pendidikan semakin tinggi dan teknologi semakin meningkat. Sebagai implikasi dari peningkatan ini diharapkan kesempatan kerja akan bertambah, tingkat pendapatan meningkat, dan kemakmuran masyarakat menjadi semakin tinggi (Sukirno, 2010: 3).

Dari penjelasan di atas sudah jelas bahwa etos kerja dan disiplin kerja sangat be rpengaruh terhadap peningkatan ekonomi suatu masyarakat. Bahkan bisa di jadikan 
tolak ukur tinggi rendahnya pendapatan ekonomi seseorang ataupun golongan tergantung bagaimana etos dan disiplin kerja yg mereka miliki .
Berdasarkan kerangka pikir yang diuraikan di atas, maka dapat digambarkan paradigma penelitian sebagaimana terlihat pada gambar.1:

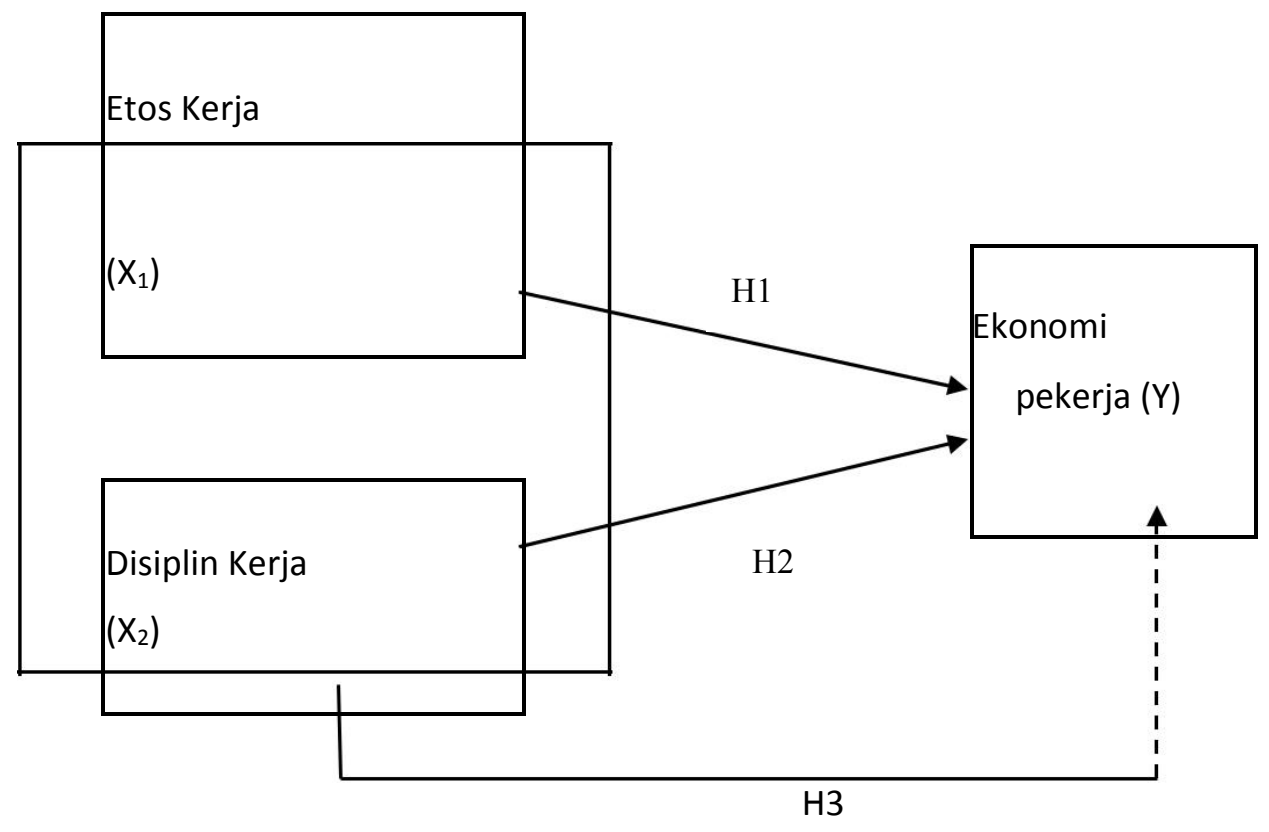

Gambar.1

\section{METODE PENELITIAN / METHODS}

Penelitian ini termasuk dalam kategori penelitian asosiatif kausal dengan menggunakan pendekatan kuantitatif. Penelitian asosiatif kausal adalah penelitian yang bertujuan untuk mengetahui tingkat pengaruh antara dua variabel atau lebih. Penelitian ini akan menjelaskan hubungan mempengaruhi dan dipengaruhi dari variabel-variabel yang akan diteliti, yaitu variabel etos kerja (X1) dan disiplin kerja (X2) terhadap variabel dependen ekonomi pekerja (Y). Pendekatan kuantitatif digunakan karena data yang akan digunakan untuk menganalisis pengaruh antar variabel dinyatakan dengan angka. Ruang lingkup penelitian terbatas pada pekerja kuli angkut (manol) di UPT TPI Mayangan yang telah bekerja dalam jangka waktu yang cukup lama dan mencari jawaban dampak etos kerja dan disiplin kerja pada peningkatan ekonomi pekerja. Populasi dalam penelitian ini adalah seluruh pekerja kuli angkut (manol) di UPT TPI Mayangan yang berjumlah 30 orang pekerja. Semua kuli di jadikan objek penelitian ini. Menurut Sekaran (2006) diperlukan ketelitian dan keyakinan dalam menentukan jumlah ukuran sampel penelitian, semakin tinggi tingkat ketelitian yang diinginkan, maka semakin besar ukuran sampel yang diperlukan.Teknik pengumpulan data untuk variable (X1) dan (X2) dilakukan menggunakan kuesioner sedangkan untuk variable (Y) di lakukan dengan wawancara. Sedangkan teknik analisis data yang di gunakan menggunakan uji $\mathrm{t}$ dan uji $\mathrm{F}$ untuk mencari regresi linier 
berganda.

HASIL PENELITIAN / RESULTS UJI REGRESI LINEAR BERGANDA
Untuk menguji hipotesis dalam penelitian ini, digunakan Uji T dan Uji F, Hasil uji T sebagaimana tabel 1.

Tabel 1

Coefficients $^{\mathrm{a}}$

\begin{tabular}{|c|c|c|c|c|c|c|}
\hline \multirow{2}{*}{\multicolumn{2}{|c|}{ Model }} & \multicolumn{2}{|c|}{ Unstandardized Coefficients } & \multirow{2}{*}{$\begin{array}{c}\text { Standardized } \\
\text { Coefficients }\end{array}$} & \multirow[b]{2}{*}{$\mathrm{t}$} & \multirow[b]{2}{*}{ Sig. } \\
\hline & & B & Std. Error & & & \\
\hline \multirow[t]{3}{*}{1} & (Constant) & 2.311 & .664 & & 3.483 & .002 \\
\hline & Etoskerja & .041 & .184 & .042 & .220 & .828 \\
\hline & disiplinkerja & -.152 & .202 & -.145 & -.752 & .458 \\
\hline
\end{tabular}

a. Dependent Variable: peningkatanekonomi

Hipotesis pertama berbunyi bahwa pengaruh etos kerja terhadap peningkatan ekonomi pekerja di UPT TPI Mayangan di tolak. Berdasarkan hasil penghitungan antara $\mathrm{T}$ hitung dan $\mathrm{T}$ tabel di temukan bahwa $\mathrm{T}$ hitung sebesar 0,220 sedangkan $\mathrm{T}$ table di dapatkan 2,052 sehingga di ketahui bahwa $\mathrm{T}$ hitung lebih kecil dari pada $\mathrm{T}$ tabel. Nilai tersebut memberi makna tidak ada pengaruh antara etos kerja terhadap peningkatan ekonomi pekerja di UPT TPI Mayangan.

Berdasarkan hasil pengamatan yang di lakukan penyebab tidak berpengaruhnya etos kerja terhadap peningkatan ekonomi pekerja adalah gaji dan kesejatheraan yang di terima pekerja tidak ada yg berbeda baik bagi pekerja yang memiliki etos kerja tinggi maupun yg memiliki etos kerja rendah. Hal ini di sebabkan oleh toleransi yang begitu tinggi terhadap pekerja.
Hipotesis ke dua berbunyi bahwa pengaruh disiplin kerja terhadap peningkatan ekonomi pekerja di UPT TPI Mayangan di tolak. Berdasarkan hasil perhitungan antara $\mathrm{T}$ hitung dan $\mathrm{T}$ tabel di temukan bahwa T Hitung sebesar -0,752 sedangkan $\mathrm{T}$ tabel di dapatkan 2,052 sehingga di ketahui bahwa $\mathrm{T}$ hitung lebih kecil dari $T$ tabel. Nilai Tersebut member makna tidak ada pengaruh antara disiplin kerja terhadap peningkatan ekonomi pekerja di UPT TPI Mayangan.

Berdasarkan hasil pengamatan yang di lakukan penyebab tidak berpengaruhnya disiplin kerja terhadap peningkatan ekonomi pekerja hal ini, karna tidak ada sistem yang baik dalam memberikan gaji, semua di gaji sama dalam setiap bulannya baik bagi pekerja yang memiliki kedisiplinan tinggi maupun bagi pekerja yang memiliki kedisiplinan rendah.

Tabel 2

ANOVA $^{b}$

\begin{tabular}{|ll|r|r|r|r|r|}
\hline Model & & Sum of Squares & Df & Mean Square & F & \multicolumn{1}{c|}{ Sig. } \\
\hline 1 & Regression & .401 & 2 & .201 & .283 & $.756^{\mathrm{a}}$ \\
& Residual & 20.567 & 29 & .709 & & \\
& Total & 20.969 & 31 & & & \\
\hline
\end{tabular}

a. Predictors: (Constant), disiplinkerja, etoskerja 
ANOVA $^{b}$

\begin{tabular}{|ll|r|r|r|r|r|}
\hline Model & & Sum of Squares & Df & Mean Square & F & Sig. \\
\hline 1 & Regression & .401 & 2 & .201 & .283 & $.756^{\mathrm{a}}$ \\
& Residual & 20.567 & 29 & .709 & & \\
& Total & 20.969 & 31 & & & \\
\hline
\end{tabular}

b. Dependent Variable: peningkatanekonomi

Berdasarkan tabel 2 dapat di nilai bahwa Hipotesis ketiga nilai $\mathrm{F}$ hitung di ketahui 0,283 sedang nilai $F$ tabel 3,32 sehingga nilai $\mathrm{F}$ hitung lebih kecil dari pada $\mathrm{F}$ tabel dan dapat di simpulkan bahwa etos kerja dan disiplin kerja secara simultan tidak berpengaruh terhadap peningkatan ekonomi pekerja di UPT TPI Mayangan.

Dari pengamatan selama meneliti semua itu di sebabkan karena tingginya toleransi dan kurang baiknya sistem penggajian di UPT TPI Mayangan.

\section{KESIMPULAN / CONCLUSSION}

Etos kerja dan disiplin kerja secara simultan maupun secara parsial tidak berpengaruh terhadap peningkatan ekonomi

\section{DAFTAR PUSTAKA / BIBLIOGRAPHY}

Anoraga, P. (1992). Psikologi Kerja. Jakarta: Penerbit PT. Rineka Cipta.

Bukhori, M. (1989). Spektrum Problematika ekonomi di Indonesia. Jakarta: Tirta Wacana Yogya.

Dodi,dkk. (2013). Khutbah Jum'at Ekonomi Syariah. Jakarta: Pusat Komunikasi Ekonomi Syariah

Erlina, H., Maro'ah, S., \& Mochklas, M. 2017. EFEKTIFITAS PENERAPAN METODE FEEDBACK TOOL FOR OPERATIONS (FTO) DALAM PENILAIAN KINERJA UNTUK PENINGKATAN KARIR KARYAWAN DI PT HM SAMPOERNA PASURUAN, JAWA TIMUR. Jurnal EKSEKUTIF, 14(2): 262-276

Fadillah. (2010). Meningkatkan Kemampuan Representasi Multipel Matematis, Pemecahan Masalah Matematis dan Self Esteem Siswa SMP melalui Pembelajaran kuli angkut. Tidak ada pengaruh tersebut disebabkan oleh terlalu tingginya toleransi dari UPT TPI Mayangan terhadap kuli angkut yang memiliki etos kerja rendah, dengan memberikan gaji yang sama dengan kuli angkut yang memiliki etos kerja tinggi. Selain itu, sistem penggajian yang lemah juga menjadi penyebab utama tidak adanya pengaruh antara disiplin kerja terhadap peningkatan ekonomi kuli.

Berdasarkan temuan penelitian, saran yang dapat disampaikan yaitu harus memperbaiki system penggajian dengan memperhatikan etos kerja dan disiplin kerja yang ada serta mengurangi sedikit rasa toleransi kepada pekerja kuli angkut yang ada di UPT TPI Mayangan.

dengan Pendekatan Open Ended. Disertasi UPI Bandung: Tidak diterbitkan.

Firmansyah, M.A., Didin Fatihudin, D., \& Mochklas, M. 2017. The Effect of Working Group, Leadership Style, Organizational Characteristics and Administrative Processes on the Job Performance of Furniture Company in Pasuruan, Indonesia. Saudi Journal of Economics and Finance, 1(1):14-19

Hani, H.T. (2008). Manajemen Personalia dan Sumber Daya Manusia. Yogyakarta: BPFE.

Hasibuan, M.S.P. (2013). Manajemen Sumber Daya Manusia. Jakarta: PT Bumi Aksara.

Helmi, (1996). Disiplin Kerja. Buletin Psikologi, Tahun IV, Nomor.2. Jakarta: PT Spirit Mahardika.

Kartajaya, H. 2006. Hermawan Kartajaya on Segmentation Seri 9 Elemen

Kuznets, S.P. S. (1971). Economics Growth of 
Nations Marketing. Bandung: PT. Mizan Pustaka.

Maslow, A.H. (2010), Motivation and Personality. Jakarta:Rajawali.

Mochklas, M., \& Mahardhika, B.W. 2019. ANALISA FAKTOR-FAKTOR PENGARUH LOYALITAS PEREMPUAN DI PERUSAHAAN KOREA SELATAN. Balance, 16(1): 112-121

Mochklas, M., Pinaraswati, S.O., \& Setiawan, T. 2018. HOW MOTIVATION WORKS, INDONESIAN EMPLOYEES IN FOREIGN COMPANIES?. SINERGI, 8(2): 26-30

Narwoko, D.J., \& Bagong, S. (2013). Sosiologi Teks Pengantar dan Terapan. Jakarta : Kencana.

Peters, A.A.G. \& Siswosoebroto, K. (1988). Perkembangan Hukum Modern dan Rasional: Sosiologi Hukum Max Weber dalam Hukum dan Perkembangan Sosial, Jakarta:Pustaka Sinar Harapan.

Samuelson, P.A. (2003). Ilmu Makro Ekonomi.
Jakarta:PT Media Global Edukasi.

Sasono, A. (2014). Pengaruh Komisaris Independen dan Komite Audit terhadap Permasalahan Agensi pada Penentuan Struktur Pembiayaan dan Kepemilikan Managerial Perusahaan. Jurnal BPPK. 7(2):123-134.

Sekaran, U. (2006). Research Methods for Business: Metode Penelitian Untuk Bisnis, Edisi ke 4 Buku 2. Jakarta:Salemba Empat.

Sinamo, J.H. (2005). Delapan Etos Kerja Professional. Jakarta: PT Spirit Mahardika.

Smith, A.

http://id.wikipedia.org/wiki/Adam Smith diakses pada 28 desember 2018

Sukirno, S. (2003). Pengantar Teori Mikro Ekonomi. Jakarta: PT. Salemba.

Sukirno, S. (2010). Makro Ekonomi Teori Pengantar. Jakarta : Raja Grafindo Persada Taringan, R. (2005). Ekonomi Regional-Teori dan Aplikasi Edisi Revisi. Bumi Aksara. Jakarta

Tasmara, T. (2002). Membudayakan Etos Kerja Islami. Jakarta: Gema Insani Wibowo. 